\title{
How Population Size Affects Party Systems and Cabinet Duration
}

\section{Introduction}

Do party system characteristics differ in small and large countries, all other conditions being the same? If they do, then what is the specific average relationship to the population, and why? One may expect that tiny countries would not have room for many parties. With fewer parties to divide the pie, the largest party's share might be larger than is the case in larger countries. Also, the governmental cabinets might have fewer parties, which might make them more stable.

All these guesses are merely directional. This means they attempt to predict the direction of change in party system when population $(P)$ changes (i.e., the sign of $d y / d P$ ). They do not specify how large the number of parties etc. might be, for a given population. A more specific prediction would be offered by a quantitative model that also stipulates the expected functional relationship (i.e., the form of $y=f[P]$ ), all other conditions having medium values. 
It is usually easier to test the direction of change than to establish the functional relationship. However, the reverse could be the case when both of the following two conditions apply:

a) The rate of change is so low that even small random fluctuations could blur the empirical trend; and

b) We have a logical model that predicts the functional form of the relationship.

Under these conditions, research emphasis changes from measuring the degree of fit of data to an empirical best fit curve, based on the same data, to testing the agreement between predicted logical relationship and data that did not enter into construction of the model.

It will be seen that this is so in the present case. The impact of population can be expected to be so mild that it is hard to prove its existence by statistical means. Yet a logical model predicts the zone of occurrence of data largely within a factor of 1.5 (meaning multiplying or dividing the mean prediction by 1.5).

We will focus on three characteristics of party systems: the effective number of legislative parties $(N)$ and largest seat share $\left(s_{1}\right)$ in the first or only chamber of the legislative assembly, and the mean duration of cabinets $(C)$ as an importance consequence of the number of parties. 


\section{Previous work}

The size $(S)$ of the first or only chamber of representative assemblies (i.e., the number of their members) was connected to the population represented $(P)$ by Taagepera (1972) both empirically and through a logical model. The simplest expression for this cube root law of assembly sizes is

$$
S=P^{1 / 3}
$$

For a population of one million, it predicts $S=100$, while for a billion it would be $S=$ 1000. Marked exceptions are relatively small island nations, whose assemblies fall short of the cube root of their populations. A number of other relationships, with predicted direction empirically confirmed, were added in the seminal work by Robert Dahl and Edward Tufte, Size and Democracy (1973).

A recent overview of 'Size and Politics' (Taagepera 2007, Chapter 12) includes more recent advances regarding party systems. Its substance will be given here very briefly, omitting most of the specific formulas. Smaller countries seem to have a lower number of parties registered (Anckar 1998, 2000). Smaller PR countries seem to have higher party memberships, per capita (Weldon 2006). Smaller FPTP countries may have a lower share of seats going to third parties (Gerring 2005). What is of most interest for the present purposes is a string of models that connects several party system indicators to assembly 
size. This is so because assembly size itself connects to population, through the cube root law.

The largest seat share $\left(s_{1}\right)$ has been shown to logically connect to the product of mean district magnitude $(M)$ and assembly size $(S)$ as

$$
s_{1}=(M S)^{-1 / 8} .
$$

For a set of 46 systems, the correlation coefficient of logarithms of $s_{1}$ and $M S$ is $R^{2}=0.51$ (Taagepera and Ensch 2006, Taagepera 2007: 129). The model applies in principle only to 'simple' electoral systems, where all seats are allocated in districts of roughly comparable magnitude, with no further complexities such as thresholds, second tiers or second rounds. Only basic list PR and FPTP qualify as simple, given that all other electoral rules add features that are not indispensable. In order to expand the sample, the set of 46 also included some Two-Rounds (TR) and Alternative Vote (AV) systems. Graphs $s_{1}$ vs. $S$ for $M=1$ systems in Taagepera and Ensch (2006) and Taagepera (2007: 126) show that TR systems involve wild randomness and reduce the overall $R^{2}$, while the single AV systems (Australia) fits into the general picture.

The effective number of parties $(N)$ also logically connects to the same 'seat product' $M S$ :

$$
N=(M S)^{1 / 6} .
$$


For a set of 25 systems, the coefficient of determination between the logarithms of $N$ and $M S$ is again $R^{2}=0.51$ (Taagepera 2007: 153).

Finally, the mean duration of cabinets $(C)$ logically connects to the number of parties and thus, more indirectly, to the seat product $M S$ :

$$
C=42 \text { years } /(M S)^{1 / 3}
$$

For the previous set of 25 systems, the correlation coefficient of logarithms of $C$ and $M S$ is $R^{2}=0.24$ (Taagepera 2007: 171; Taagepera and Sikk 2010). Increased scatter, compared to $N$, reflects the more indirect nature of the connection. The data set includes all those systems for which Lijphart (1999) offers cabinet duration ${ }^{1}$ figures and which have almost simple electoral systems: FPTP, simple list PR, and also Single Transferable Vote (STV), Single Non-Transferable Vote (SNTV), and TR. The constant value $k=42$ years is the one that best fits the more direct model $C=k / N^{2}$. No $M$ or $S$ data enter into the determination of $k$.

Party and electoral systems interact of course in both directions. Existing party constellations are a most important factor in the choice of electoral rules (Colomer 2005). Once fixed, the electoral rules continue exerting pressure on the number of parties both directly through the mechanical and indirectly through the psychological effect (Duverger 1951, Benoit 2002). Our objective here is to assess the aggregate relationship between 
country size/electoral rules and party system characteristics without trying to distinguish between the two effects.

Taagepera (2007: 191) points out that combining these models with the cube root law of assembly sizes leads to expecting a connection between the party system characteristics and population:

$$
\begin{aligned}
& s_{1}=M^{-1 / 8} P^{-1 / 24}, \\
& N=M^{1 / 6} P^{1 / 18}, \text { and } \\
& C=42 \operatorname{years}\left(M^{-1 / 3} P^{-1 / 9}\right) .
\end{aligned}
$$

Population enters with horrendously low exponents, however. On logarithmic graphs of $s_{1}, N$ and $C$ vs. $P$, with equal scales on both axes, one would expect straight lines with absolute values of slopes $1 / 24=0.0417,1 / 18=0.0555$ and $1 / 9=0.111$, respectively, for a given value of $M$. These slopes are so close to zero that even minor random fluctuation could reverse the apparent direction of the linear regression slope. Given such indeterminacy, Taagepera (2007: 191-2) does not even try to test the equations for $s_{1}$ and $N$. For $C$, the geometric means for 8 smaller and 6 larger systems using one-seat districts are compared. The larger countries tend indeed to have shorter cabinets (5.8 vs. 7.6 years), but the ratio is only 1.3 , as compared to the expected 1.6. In the following, an attempt is made to go further. 
Many studies in political science aim at empirical accounting for outputs, trying to include all variables that conceivably could affect the output. Visibly, our aim is quite different and should not be mistaken for empirical data fit. We aim at testing the impact of a single factor, population, as predicted by a logical quantitative model. The model used indicates that population interacts with district magnitude in a specific way. Thus we have to include the latter - but, giving more than lip service to Occam's Razor, we include no more variables. Factors such as the number of social conflicts, including ethnic fractionalization (Amorim Neto and Cox 1997, Clark and Golder 2006, Mozaffaret al. 2003, Ordeshook and Shvetsova 1994, Singer and Stephenson 2009, Stoll 2008, Stoll 2011, Taagepera 1999, Taagepera and Grofman 1985) federalism and the extent to which district-level parties aggregate on national level (Chhibber and Kollman 1998, 2004, Chhibber and Murali 2006, Hicken 2009) and parliamentarism/presidentialism (Filippov et al. 1999, Golder 2006, Hicken and Stoll 2011, Jones 1994, Lijphart 1994, Shugart and Carey 1992) may also affect the outputs considered, but the issue here is not maximal accounting for these outputs but testing 1) whether population has any impact in the predicted direction (all other factors being more or less random), and more demandingly, 2) whether it has the degree of impact predicted by the model.

\section{The model and data}

To the extent that the cube root law is valid, the seat product $M S$ at the core of the previous equations in $s_{1}, N$ and $C$ becomes 


$$
M S=M\left(P^{1 / 3}\right)=\left(M^{3} P\right)^{1 / 3}
$$

\section{Hence}

$$
\begin{aligned}
& s_{1}=\left(M^{3} P\right)^{-1 / 24}, \\
& N=\left(M^{3} P\right)^{1 / 18}, \text { and } \\
& C=42 \operatorname{years}\left(M^{3} P\right)^{-1 / 9} .
\end{aligned}
$$

If so, then the logarithms of $s_{1}, N$ and $C$ should have linear relationships to the logarithm of $\left(M^{3} P\right)^{1 / 3}$.

In the special case of $M=1$, the equations above simplify to

$$
\begin{aligned}
& s_{1}=P^{-1 / 24}, \\
& N=P^{1 / 18}, \text { and } \\
& C=42 \text { years } P^{-1 / 9} .
\end{aligned}
$$


We will first test this simple case, by comparing the logarithms of output variables to $\log P$. The advantage of this approach is that no assumptions regarding the impact of $M$ have to be made. The disadvantage is that the range of $P$ with the appropriate exponent is very narrow. For populations ranging from 10,000 to 1 billion, $P^{1 / 18}$ ranges only from 1.67 to 3.16. Even minor random fluctuations in $N$ can blur out trends when the range of the input variable is so narrow. It's worse for $s_{1}$ and only slightly more promising for $C$.

Next, we will test the more general case that includes $M>1$, by comparing the logarithms of output variables to $\log \left(M^{3} P\right)$. The advantage here is that the range of $\log \left(M^{3} P\right)$ is much wider than that of $\log P$. Hence, with the same degree of random fluctuations in $N$, trends can become more visible. The disadvantage is that success depends on the correctness of the assumption that multi-seat districts magnify the impact of population by a factor $M^{3}$. If this assumption does not hold, we risk with false negatives. Note however that false positives are extremely unlikely, as it would require that the error on the impact of $M$ exactly cancels out the error on the impact of $P$.

Included in the analysis are democracies with simple electoral systems (those where all seats are allocated in districts, in a single round, with no legal thresholds) for which the relevant data for $s_{1}, N$ and $C$ is available (tabulated in Taagepera and Sikk, 2010), adding mean population figures for the relevant periods as estimated from Atlas of World

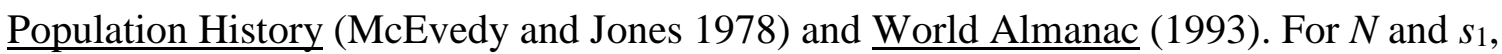
we also consider further countries tabulated in Taagepera and Ensch (2006), which extends the population range toward lower $P$. We exclude the two rounds systems, 
because they are unpredictable in votes-seats transformations (Taagepera 2007: 54, 72) so that the models for simple electoral systems clearly do not apply to them. This leaves us with a main list (Table 1) of 24 systems with $M=1$ (one of them Alternative Vote = STV) and 11 with $M>1$ (including two STV and one SNTV).

The values shown for $S, s_{1}, N$ and $C$ are geometric means of values for individual elections. ${ }^{2}$ Populations are approximate geometric means of the extremes over the period. The impact of minor changes in population is muted by the exponents applied in the models, ranging from $1 / 9$ to $1 / 24$. The largest variation in population occurred in Costa Rica - from 1 to 3.7 million, with a geometric mean at roughly 2 million. Even if the mean should be off by half a million - i.e. by a factor of $2.5 / 2=1.25$ - it would alter our estimate of mean cabinet duration by a factor of $1.25^{1 / 9}=1.025$; the estimates of the effective number of parties and the largest seat share would be affected much less. ${ }^{3}$

\section{[TABLE 1 ABOUT HERE]}

\section{Results}

$\underline{\text { Party system predicted from population alone: } \mathrm{M}=1 \text { systems }}$

We will proceed in two stages, first assessing the mean predictions and thereafter looking at the fit of actual data with lines proposed by the theoretical models. The logical models above predict the average levels around which the fluctuation should take place. For the $24 M=1$ systems in Table 1, mean populations for the periods considered range from 
0.017 million for Cook Islands to 800 million for India, with a geometric mean of 1.14 million. Table 2 shows the values calculated using the equations above, the actual geometric means, and the percent difference.

\section{[TABLE 2 ABOUT HERE]}

The geometric mean values of the largest seat share, effective number of parties, and mean cabinet duration are predicted by the logical model within $9 \%$ or better, based on nothing but population. The logical causal concatenation on which the model in Taagepera (2007) is built is $P \rightarrow S \rightarrow s_{1} \rightarrow N \rightarrow C$. Thus the error would be expected to increase in that order. Surprisingly, this is not the case. The mean prediction for assembly size is strongly off. This is due to sixteen of the countries being small island nations that tend to have disproportionally small parliaments (see Taagepera 1972). Yet the later predictions further down in the causal chain are off by much less, suggesting that population may additionally have a direct impact on party systems, bypassing assembly size.

Yet graphing the largest seat share against population shows only a faint trend. Figure 1 graphs $s_{l}$ against $P$, both on logarithmic scales. Also shown are the lines corresponding to the prediction $s_{1}=P^{-1 / 24}$ and to deviations from it by a factor of 1.5 , i.e., $s_{1}=(3 / 2) P^{-1 / 24}$ and $s_{1}=(2 / 3) P^{-1 / 24}$. All the data points are within this range of error, and the geometric means of both sets are close to the predicted line. Yet the linear regression line is much 
gentler than the prediction and the fit is poor. ${ }^{4}$ The picture is similar for the effective number and mean cabinet duration (graphs not shown). What does it mean?

This is another instance where a purely statistical approach cannot substitute for logical models (cf. Taagepera 2008) and would lead us astray. Compared to the range of random fluctuation, the range of the input variable is just too narrow to test for the expected slope. We have to find ways to extend this range - and this is where multi-seat systems come in.

[FIGURE 1 ABOUT HERE]

Party system predicted from population and district magnitude

Table 3 shows the geometric means for multi-seat electoral systems listed in Table 1. Here the mean for assembly size is close to the cube root of mean population, as only 2 of the 11 countries are relatively small. The basis for calculating the mean $s_{1}, N$ and $C$ now shifts from mean $P$ to mean $M^{3} P$. The actual means are predicted within $19 \%$. Here we faced a double risk. The model for the effect of population as such could be off, or the model for combining population and district magnitude could be off. The quality of the prediction offers some confidence on both accounts.

[TABLE 3 ABOUT HERE] 
Figure 2 graphs the largest seat share against the product $M^{3} P$, both on logarithmic scales. Different symbols are used for $M=1$ and $M>1$ systems and the mean points for the two sets are shown with bold symbols. Also shown are the lines corresponding to the prediction $s_{1}=\left(M^{3} P\right)^{-1 / 24}$ and to deviations from it by a factor of 1.5 . All the data points are within this range of error, and the geometric means of the three sets are close to the predicted line.

[FIGURE 2 ABOUT HERE]

For $M=1$ systems, the data cloud exactly replicates Figure 1 . Yet the overall picture is quite different, as the inclusion of $M>1$ systems doubles the range of the input variable. The linear regression line now approaches the expected line: $s_{1}=0.981\left(M^{3} P\right)^{-0.034} \rightarrow$ $\log s_{1}=-0.019-0.034 \log \left(M^{3} P\right)$, as compared to the expected $s_{1}=M^{3} P^{-1 / 24} \rightarrow \log s_{1}=0-$ $0.0416 \log \left(M^{3} P\right)$. The precise location of the regression line is still at the merci of a few outliers - Israel and The Netherlands at the very high end of the scale. The more important question is to what degree the logical model-based line accounts for the variation in data, compared to the statistical best fit line. The standard error of estimate (SEE) is 0.17 for the OLS best fit and 0.20 for the theoretical model - not appreciably less given the mean of $\log _{s_{1}}=-0.60\left(\mathrm{R}^{2}\right.$ correspondingly 0.55 and 0.35$) .{ }^{5}$ The model's goodness of fit is strongly affected by the outliers of Finland, Israel and The Netherlands. The upper end of the $M^{3} P$ scale is sparsely populated as we are limited to simple electoral systems here, while systems with $M \gg>1$ systems tend to use legal thresholds or multiple tiers of seat allocation. Rough approximations of predicted largest party's seat share in 
five European democracies with $M^{3} P$ ranging from 47 to 270 billion presented in Appendix B conform reasonably well to the theoretical model.

Similarly, Figure 3 graphs the effective number of parties against the product $M^{3} P$, for data in Table 1. The geometric means of the two sets are close to the predicted line. Only two countries deviate from expectation by more than a factor of 1.5 , in opposite directions. Papua New Guinea had a profusion of tribally based parties, while Botswana had only one large and one small party, both based on ethnic identity. SEE and $R^{2}$ are heavily affected by Papua New Guinea. High levels of ethnic fractionalization have been shown to increase $N$ (Singer and Stephenson 2009) - Papua New Guinea 'approximates a perfectly fractionalized state' (Fearon 2003: 205) and as it deviates by more than two standard deviations from the best fit line, its exclusion is justified because of potentially massive impact of ethnic heterogeneity. Without Papua New Guinea, the regression line is $N=0.928\left(M^{3} P\right)^{0.055} \rightarrow \log N=-0.075+0.055 \log \left(M^{3} P\right)$, as compared to the expected $N$ $=\left(M^{3} P\right)^{1 / 18} \rightarrow \log N=0-0.056 \log \left(M^{3} P\right)$. Here too, the observations do not deviate from theoretically based predictions appreciably more than from those based on OLS estimation (see Figure 4) and the model-based line has a SEE (0.21) very close to that of OLS regression (0.19) (correspondingly, $R^{2}=0.66$ versus $\left.R^{2}=0.72\right){ }^{6}$

[FIGURE 3 ABOUT HERE]

[FIGURE 4 ABOUT HERE] 
Finally, Figure 5 graphs the mean duration of cabinets against the product $M^{3} P$ for the 24 systems for which the data are available. Once more, the geometric means of the two sets are close to the predicted line, but nine systems deviate from expectation by more than a factor of 1.5, in opposite directions. For Papua New Guinea and Botswana, the deviations in cabinet duration are logical consequences of their unusual effective numbers of parties. While these cases can be explained, there is no obvious way to account for the opposite deviations of stable democracies such as Finland and The Netherlands, except for acknowledging their deviant party systems (see Figure 2 and 3). In the logical causal concatenation $P \rightarrow S \rightarrow s_{1} \rightarrow N \rightarrow C$, cabinet duration is simply so far removed from population that the latter's impact becomes blurred.

[FIGURE 5 ABOUT HERE]

Statistically speaking, exclusion of no country is justified here. The regression line is $\log C=\log (36.3 \mathrm{yrs})-0.096 \log \left(M^{3} P\right)$. It is still not far off the expected $\log C=$ $\log (42 \mathrm{yrs})-0.11 \log \left(M^{3} P\right)$, particularly in the middle of the data cloud. Once again, the model-based line fits the data as well as the OLS line: for theoretical model, SEE $=0.65$ and for OLS model SEE $=0.63\left(R^{2}=0.33\right.$ versus $R^{2}=0.38$, respectively $)$. What matters is that the predicted zone still includes two-thirds of the data points and the rest is positioned evenly around it. 


\section{$\underline{\text { Nationwide PR elections }}$}

For nationwide PR elections, district magnitude equals assembly size: $M=S$. Then, to the extent that the cube root law is valid, $M^{3}=S^{3}=P$, so that the core expression $M^{3} P$ becomes $P^{2}$. The previous equations in $s_{1}, N$ and $C$ simplify into

$$
\begin{aligned}
& S_{1}=P^{-1 / 12}, \\
& N=P^{1 / 9}, \text { and } \\
& C=42 \text { years } P^{-1 / 4.5} .
\end{aligned}
$$

With increasing population, these values change much more rapidly than is the case with one-seat districts.

Testing is difficult because most countries with nationwide PR balance it with appreciable legal thresholds on votes, so as to keep the number of parties down. Table 1 includes only two systems with nationwide PR, and even these have mild thresholds: $1 \%$ for Israel and $0.67 \%$ for The Netherlands. Table 4 shows the degree of agreement. The actual values are off in the direction expected when legal thresholds are applied. They are off by up to $35 \%$, except for cabinet duration for The Netherlands, which is much higher than expected (cf. Figure 4).

[TABLE 4 ABOUT HERE] 
$\underline{\text { Logically predictable effect, largely blurred by other factors }}$

A look at Figures 2 to 4 confirms that population does affect the largest seat share, the effective number of parties and mean duration of cabinets, conjointly with district magnitude, for simple electoral systems. All other factors (and district magnitude in particular) being the same, larger countries have smaller seat shares going to the top party. Larger countries tend to have more parties and shorter cabinets. The effect of $\log M^{3} P$ remains robust when controlling for other factors that may affect party systems and cabinet durations, such as ethnic fractionalization, presidentialism and federalism. When introduced in OLS models on their own or in interaction with district size, only the effect of fractionalization is statistically significant $(\mathrm{p}<0.05)$ on $\log s 1$ and $\log N$, with Papua New Guinea having high leverage. ${ }^{7}$

It is important to go beyond these directional conclusions. The party system characteristics of most systems can be predicted within a factor of 1.5 using a logical model that combines population and district magnitude. For countries using one-seat districts, this boils down to predicting party system characteristics based solely on population.

Over large differences in population, these logical predictions vary appreciably. For an FPTP country of 100,000, an effective number of parties of 1.9 would be predicted, while it would be 2.8 for an FPTP country of 100 million (see Figure 5), and 3.6 for a country of 100,000 that applies nationwide PR. The respective largest seat shares would be $62 \%$, 
$46 \%$ and $39 \%$. The expected cabinet durations would be $11.5,5.3$ and 3.2 years, respectively.

\section{[FIGURE 6 ABOUT HERE]}

The catch is that the largest seat shares of individual countries are observed to vary within a factor of 1.4 of these averages (cf. Figures 1 and 2). Deviations are even larger for the effective number of parties (Figure 3) and especially for cabinet duration (Figure 4). Within such a range, countries have appreciable leeway. This leeway is more limited, if countries wish to adhere to a definite brand of democracy, as discussed next.

\section{Population dependency of the majoritarian and consensus models of democracy}

Consider first countries determined to hold on to FPTP. Such countries probably have in mind the majoritarian ideal of a single-party cabinet and a mostly single-party opposition of an almost equal strength, such as in 52-48, with regular alternation in power at every election but no cabinet change in between. This would mean $s_{1}=0.52, N=2.00$ and $C=$ 4 years (assuming elections every 4 years). Does population place limitations on reaching such an average outcome?

Data scatter in Figure 1 shows that a largest seat share of $52 \%$ has been obtained with populations as low as 40,000 and as high as 70 million. This covers most of the entire range of sovereign countries. However, most countries of less than one million tend to 
have an overly dominant largest party, facing a combined opposition reduced to less than one-third of the seats. The majoritarian ideal of a strong opposition seems hard to reach in very small countries.

For the effective number of parties to range around 2 (say, from 1.8 to 2.2), populations in Figure 3 are observed to range from 2 to 50 million. Below 1 million, the preponderance of the largest party reduces $N$ to appreciably less than 2 . On the high side, countries above 10 million population tend to have $N$ larger than 2.2 , reflecting thirdparty incidence.

As for duration of cabinets, no $M=1$ systems in Figure 4 happen to have mean durations around 4 years. Durations are either below 3 years, denoting frequent cabinet changes in between elections, or above 6 years, denoting the same party remaining in power for a second or even third term in a row. Our model predicts that regular alternation every 4 years would be the likeliest for very large countries. The only actual case (India), however, has had appreciably more frequent changes.

In sum, for $M=1$ countries our model predicts that the majoritarian ideal could be best satisfied by populations around ten million on the account of largest seat share, around 0.5 million on the account of effective number of parties, and rather incongruously, around 1 billion for cabinet duration. In this light, the ideal of two party alternation may involve an internal contradiction. 
Actual data suggest that countries below one million have major difficulties in holding up the majoritarian ideal. Their largest party tends to dominate the assembly excessively, reducing the 2-party system to a one-and-a-half party system. Moreover, the same party tends to be in power for several electoral periods in a row. The mechanism behind this outcome is rooted in an excessive largest party bonus in conversion of vote shares to seat shares, due to small assembly sizes - see Lijphart (1990). At the other extreme, very populous FPTP countries might be expected to have difficulty avoiding strong third parties, but actual evidence is inconclusive.

Shifting now to multi-seat PR systems, many of them conform to the consensus model as described by Lijphart (1999), with a large effective number of parties, small largest seat share, and frequently reshuffled coalition cabinets. However, these are not explicit goals, such as single party majorities and two-party alternation are for the majoritarian model. They are merely the outcomes, once the electoral system allows for small party representation. Maximal small party representation is achieved with nationwide PR. In the absence of legal thresholds, the model predicts an effective number of 2.8 parties even for a population of 10,000 . The largest party would have $47 \%$ of the seats and cabinets would last 5.5 years, on the average. Consensual countries usually have a more fractionalized party system than that.

A population of 10 million could expect an effective number of parties of $N=6$. The largest party would have only $26 \%$ of the seats and cabinets would be reshuffled once every 1.2 years, on the average. This is about the most fractionalized party system that we 
observe among those that still have some stability. Larger countries than 10 million would have to avoid nationwide PR or add restrictive legal thresholds.

\section{Conclusions}

Scientists going beyond pure empirics should find it exciting that the means of some party system characteristics at given population can be predicted without any data input, solely on the basis of population, using a set of logical models. These characteristics are the seat share of the largest party and the effective number of assembly parties. The mean duration of cabinets can be added to the list. ${ }^{8}$ The solely population based prediction applies to First-Past-The Post and possibly to other single-round one-seat electoral systems. By multiplying the population by the cube of district magnitude - another logically motivated step - the prediction can be extended to those multi-seat electoral systems where all seats are allocated within districts. In all this, political science proceeds beyond empirical description to quantitative prediction on logical grounds.

The theoretical model presented and tested in this article is concerned with an indirect link between country size a party system - i.e. working through assembly size. There is no evidence for an additional direct effect on the effective number of parties and cabinet duration, as the residuals (i.e. ratios of actual to theoretically expected $N$-s and $C$-s) are not correlated with country size. When it comes to the size of the largest party, increasing population reduces it somewhat less than predicted by our model (see Figure 7). Yet, the

effect is mild at best and we currently lack a theoretical model to explain the empirical 
discrepancy. This is also well visible in Figure 2 where the slopes for theoretical and empirical fit lines differ much more than for $\mathrm{N}$ and $\mathrm{C}$. Therefore, we broadly agree with Dahl \& Tufte that all modern democracies are too populous for there to be any discernible direct effects - these may appear on the level of municipal party systems (1973: 94-97). The proposed and tested model can be used as a baseline for studies on any direct effects or the impact of other societal factors that may affect party systems and cabinet duration (including analysis of individual cabinets rather than aggregate measures as is the case here).

\section{[FIGURE 7 ABOUT HERE]}

While population has a definite overall effect on size characteristics of party systems, for individual countries this effect is heavily blurred by other factors. Only First-Past-The Post countries of less than one million are markedly hemmed in; they could expand their one-and-a-half party systems only by shifting to PR. Thus population is not destiny, as far as party system is concerned.

What are the practical implications? Countries are not prisoners of their population sizes. They are not locked in regarding their choice of party systems. Although we are far from such determinism, population still puts some limits on party systems.

\section{Appendix A. Summary of Models}


[TABLE 5 ABOUT HERE]

\section{Appendix B: Testing the Theoretical Model in Complex Electoral Systems}

Most countries that employ proportional representation use legal thresholds or multi-tier seat allocation. In such systems, $M$ is impossible to determine exactly. However, approximations can in many cases be calculated based on a premise that if a legal threshold is used, the electoral system functions roughly as a single nationwide constituency with estimated effective magnitude

$M_{\text {eff }}=\left(75 \% / T_{\text {legal }}\right)-1($ Taagepera 2007: 246).

While such estimates are rough, great precision is not of paramount importance here. Even if the estimated effective magnitude is off the 'real' $M_{e f f}$ by a factor of two, the prediction of $s_{1}$ is only off by less than $10 \%$, and by about $5 \%$ for an error within a faction of 1.5 in $M_{\text {eff. }}$

The estimates of $M$ for complex systems are interesting as they enable us to add data to the sparsely populated higher end of $M^{3} P$. Table 6 shows the estimates together with predicted and actual values of $s_{1}$ in five European democracies where we would expect high values of $M^{3} P$. The predicted values for $s_{1}$ are remarkably close to actual $s_{1}$ in most cases. Adding the approximations to the dataset would bring the OLS coefficient for 
$\log M^{3} P$ closer to theoretical $-0.042(-0.034 \rightarrow-0.037)$ and enhance the fit with the theoretical model (SEE: $0.20 \rightarrow 0.19, \mathrm{R}^{2}: 0.35 \rightarrow 0.49$ ). It suggests that the countries with high $M^{3} P$ included in our main dataset may in fact be outliers and if more countries could be added, the goodness of fit for the model would be improved (see Figure 8).

[TABLE 6 ABOUT HERE]

[FIGURE 8 ABOUT HERE]

\section{References}

Achen, Christopher H. (1990) 'What Does “Explained Variance” Explain?: Reply', Political Analysis 2: 173-84.

Alesina, Alberto, Arnaud Devleeschauwer, William Easterly, Sergio Kurlat and Romain Wacziarg (2003) 'Fractionalization', Journal of Economic Growth 8: 155-94.

Amorim Neto, Octavio and Gary W. Cox (1997) 'Electoral Institutions, Cleavage

Structures, and the Number of Parties', American Journal of Political Science 41: 149-74.

Anckar, Carsten (1998) Storlek och partisystem: En studie av 77 stater [Size and party system: A study of 77 states]. Åbo: Åbo Akademi University Press.

Anckar, Carsten (2000) 'Size and Party System Fragmentation', Party Politics 6: 305-28. 
Benoit, Kenneth (2002) 'The endogeneity problem in electoral studies: a critical reexamination of Duverger's mechanical effect', Electoral Studies 21: 35-46.

Chhibber, Pradeep and Ken Kollman (1998) 'Party Aggregation and the Number of Parties in India and the United States', American Political Science Review 92: 329-42.

Chhibber, Pradeep and Ken Kollman (2004) The Formation of National Party Systems: Federalism and Party Competition in Canada, Great Britain, India, and the United States. Princeton, NJ: Princeton University Press.

Chhibber, Pradeep and Geetha Murali (2006) 'Duvergerian Dynamics in the Indian States: Federalism and the Number of Parties in the State Assembly Elections', Party Politics 12: 5-34.

Clark, William R. and Matt Golder (2006) 'Rehabilitating Duverger's Theory: Testing the Mechanical and Strategic Modifying Effects of Electoral Laws', Comparative Political Studies 39: 679-708.

Colomer, Josep M. (2005) 'It's Parties That Choose Electoral Systems (or, Duverger's Laws Upside Down)', Political Studies 53: 1-21.

Dahl, Robert A. and Edward R. Tufte (1973) Size and Democracy. Stanford, CA: Stanford University Press.

Dodd, Lawrence C. (1976) Coalitions in Parliamentary Government. Princeton, NJ: Princeton University Press. 
Duverger, Maurice (1951) Political Parties: Their Organization and Activity in the Modern State. New York: Wiley.

Fearon, James D. (2003) 'Ethnic and Cultural Diversity by Country’, Journal of Economic Growth 8: 195-222.

Filippov, Mikhail G., Peter S. Ordeshook and Olga V. Shvetsova (1999) 'Party fragmentation and presidential elections in post-communist democracies', Constitutional Political Economy 10: 3-26.

Gerring, John (2005) ‘Minor Parties in Plurality Electoral Systems', Party Politics 11: 79-107.

Golder, Matt (2006) 'Presidential Coattails and Legislative Fragmentation', American Journal of Political Science 50: 34-48.

Hicken, Allen (2009) Building Party Systems in Developing Democracies. Cambridge: Cambridge University Press.

Hicken, Allen and Heather Stoll (2011) 'Presidents and Parties: How Presidential Elections Shape Coordination in Legislative Elections', Comparative Political Studies 44: 854-83.

Jones, Mark P. (1994) 'Presidential Election Laws and Multipartism in Latin America', Political Research Quarterly 47: 41-57.

Kvalseth, Tarald O. (1985) 'Cautionary note about $\mathrm{R}^{2}$, American Statistician 39: 279-85. 
Lewis-Beck, Michael and Andrew Skalaban (1990) 'The $R$-Squared: Some Straight Talk', Political Analysis 2: 153-71.

Lijphart, Arend (1990) 'Size, Pluralism, and the Westminster Model of Democracy: Implications for the Eastern Caribbean'. In Jorge Heine (ed) A Revolution Aborted: The Lessons of Grenada, pp. 321-40. Pittsburgh, PA: University of Pittsburgh Press.

Lijphart, Arend (1994) Electoral Systems and Party Systems: A Study of Twenty-Seven Democracies, 1945-1990. Oxford: Oxford University Press.

Lijphart, Arend (1999) Patterns of Democracy: Government Forms and Performance in Thirty-Six Countries. New Haven, CT: Yale University Press.

Mackie, Thomas T. and Richard Rose (1974) International Almanac of Electoral History. London: MacMillan.

McEvedy, Colin and Richard Jones (1978) Atlas of World Population History. New York, NY: Penguin Books.

Mozaffar, Shaheen, James R. Scarritt and Glen Galaich (2003) 'Electoral Institutions, Ethnopolitical Cleavages, and Party Systems in Africa’s Emerging Democracies', American Political Science Review 97: 379-90.

Nohlen, Dieter (ed) (2005) Elections in the Americas. Vols. 1-2. Oxford: Oxford University Press.

Nohlen, D., Florian Grotz and Christof Hartmann (eds) (2001) Elections in Asia and the Pacific: A Data Handbook: Volume II: South East Asia, East Asia, and the South Pacific: 
South East Asia, East Asia and the South Pacific. Vol. 2. Oxford: Oxford University Press.

Ordeshook, Peter C. and Olga V. Shvetsova (1994) 'Ethnic Heterogeneity, District Magnitude, and the Number of Parties', American Journal of Political Science 38: 10023.

Shugart, Matthew S. and John M. Carey (1992) Presidents and assemblies: constitutional design and electoral dynamics. Cambridge: Cambridge University Press.

Singer, Matthew M. and Laura B. Stephenson (2009) 'The political context and Duverger's theory: Evidence at the district level', Electoral Studies 28: 480-91.

Stoll, Heather (2008) 'Social Cleavages and the Number of Parties: How the Measures You Choose Affect the Answers You Get', Comparative Political Studies 41: 1439-65.

Stoll, Heather (2011) 'Dimensionality and the number of parties in legislative elections', Party Politics 17: 405-29.

Taagepera, Rein (1972) ‘The Size of National Assemblies’, Social Science Research 1: $385-401$.

Taagepera, Rein (1999) 'The Number of Parties as a Function of Heterogeneity and Electoral System', Comparative Political Studies 32: 531-48.

Taagepera, Rein (2007) Predicting Party Sizes: The Logic of Simple Electoral Systems. Oxford: Oxford University Press. 
Taagepera, Rein (2008) Making Social Sciences More Scientific: The Need for Predictive Models. Oxford: Oxford University Press.

Taagepera, Rein and Bernard Grofman (1985) 'Effective size and number of components', Sociological Methods \& Research 10: 63-81.

Taagepera, Rein and John Ensch (2006) 'Institutional Determinants of the Largest Seat Share', Electoral Studies 25: 760-75.

Taagepera, Rein and Allan Sikk (2010) 'Parsimonious Model for Predicting Mean Cabinet Duration on the Basis of Electoral System', Party Politics 16: 261-81.

Weldon, Steven A. (2006) 'Downsize My Polity? The Impacts of Size on Party Membership and Member Activism', Party Politics 12: 467-81.

Wilcox, Rand R. (2005) Introduction to Robust Estimation and Hypothesis Testing. $2^{\text {nd }}$ Edition. Amsterdam: Elsevier.

World Almanac (1992) The World Almanac and Book of Facts 1993. New York, NY: Pharos Books. 


\section{FIGURES}

Figure 1 The largest seat share vs population for $M=1$ countries

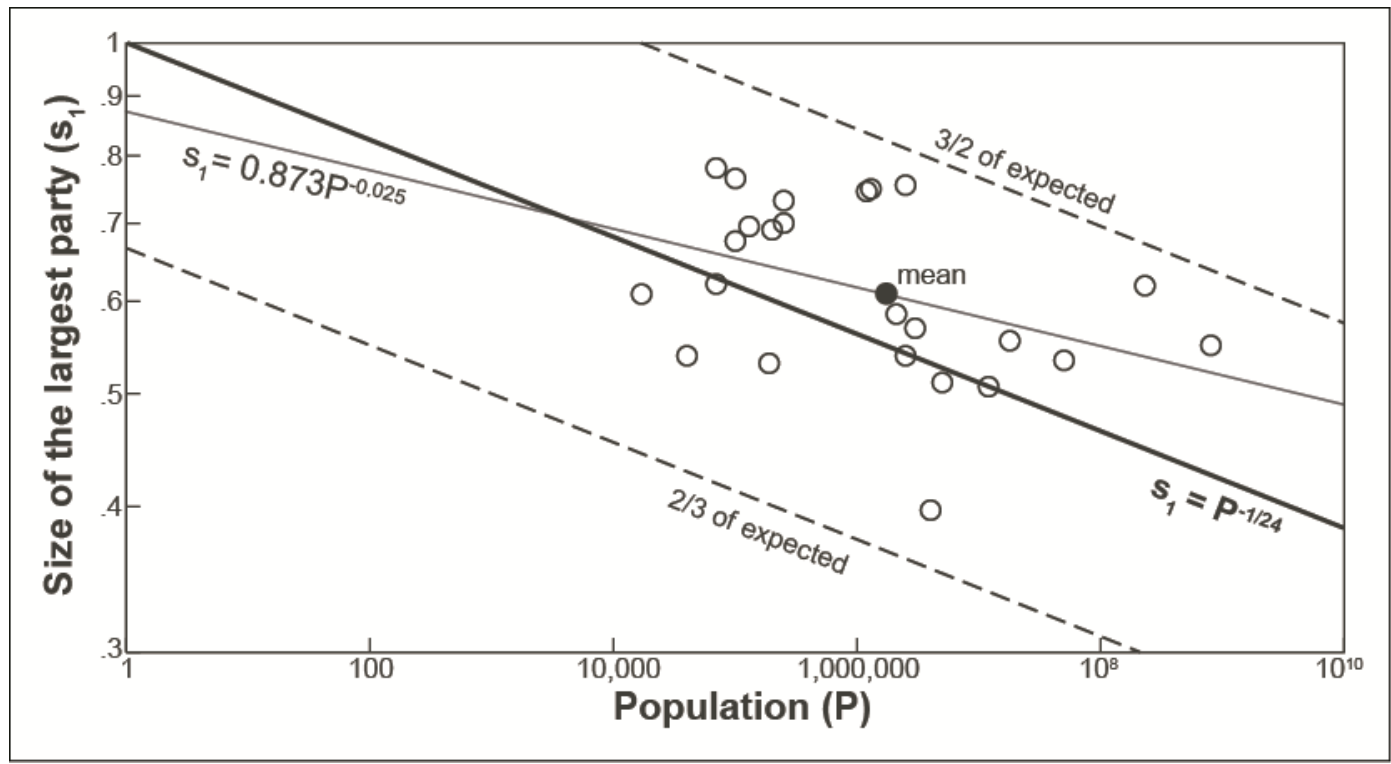

Notes: Bold line: theoretically based prediction $\left(\mathrm{R}^{2}=-0.22\right.$, i.e. the sum of squared distances

from mean $s_{l}$ is smaller than the sum of squared distances from values predicted by the model.)

Thin line: OLS best fit between logarithms $\left(\mathrm{R}^{2}=0.17\right)$

Figure 2. The largest seat share vs the product of population and district magnitude cubed.

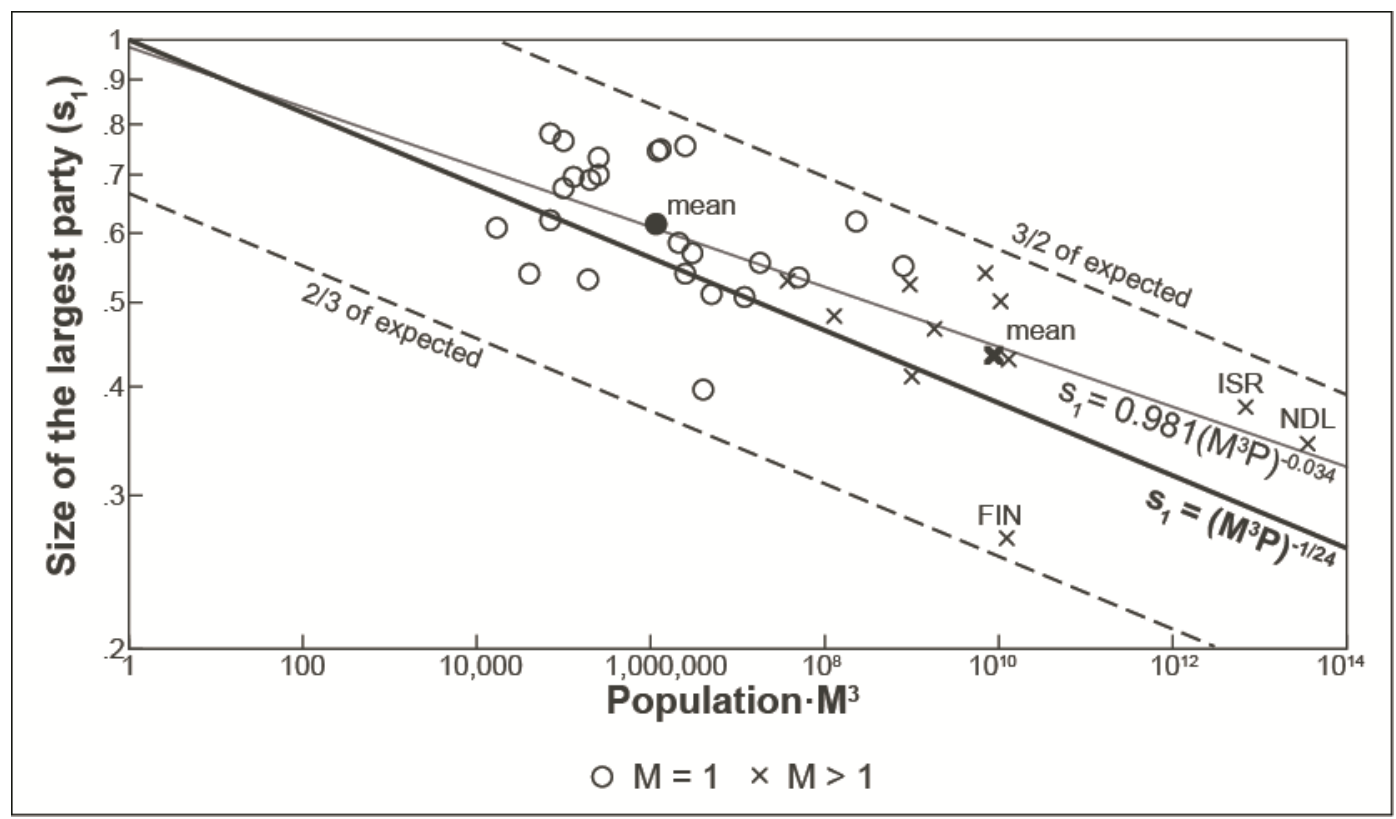

Notes: 
Bold line: theoretically based prediction $\left(\mathrm{R}^{2}=0.35\right)$. Thin line: OLS best fit between logarithms $\left(\mathrm{R}^{2}=0.55\right)$

Figure 3. Effective number of assembly parties vs the product of population and district magnitude cubed.

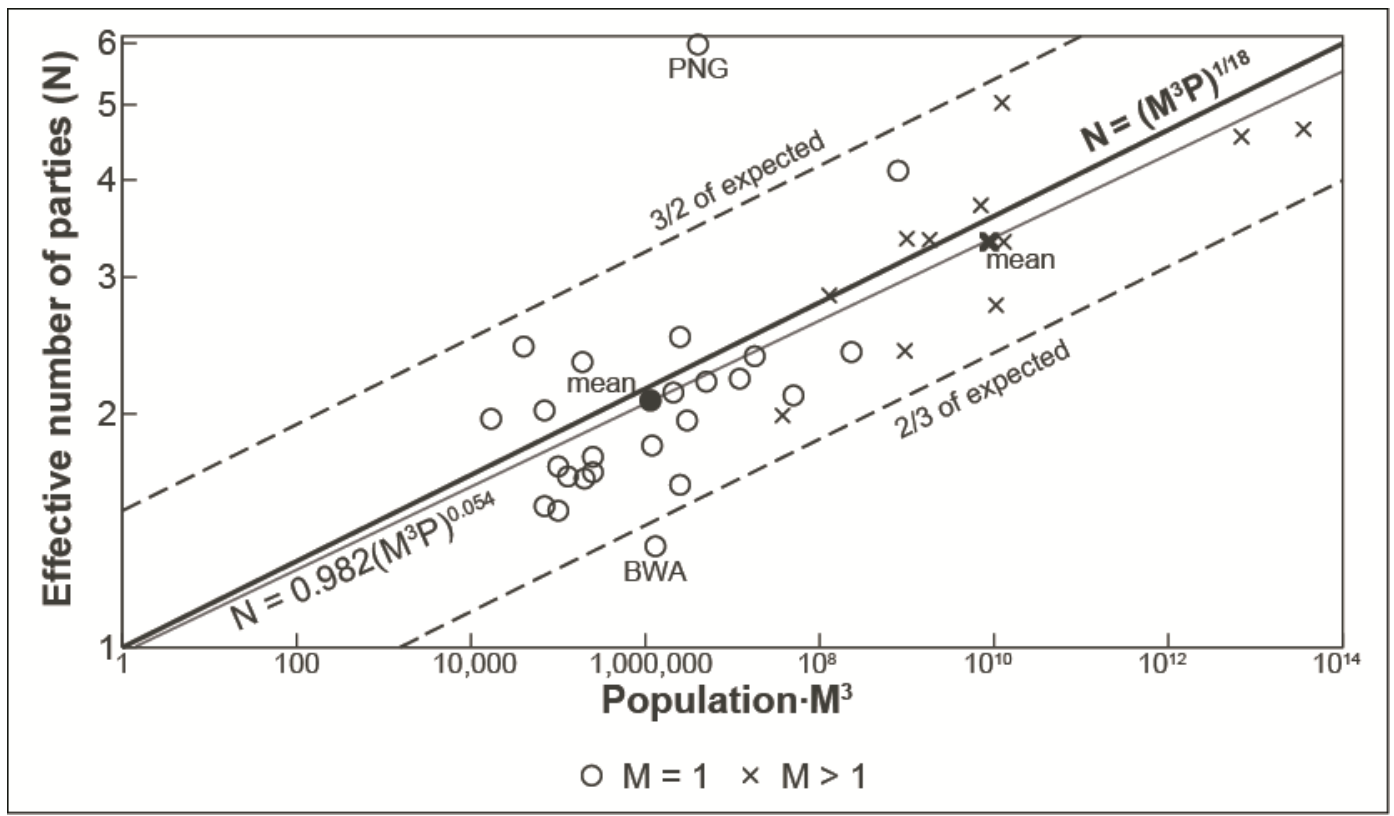

Notes: Bold line: theoretically based prediction $\left(\mathrm{R}^{2}=0.54\right)$. Thin line: OLS best fit between logarithms $\left(\mathrm{R}^{2}=0.56\right)$ 
Figure 4. Deviation from theoretically predicted N vs $\mathrm{N}$ predicted by regression.

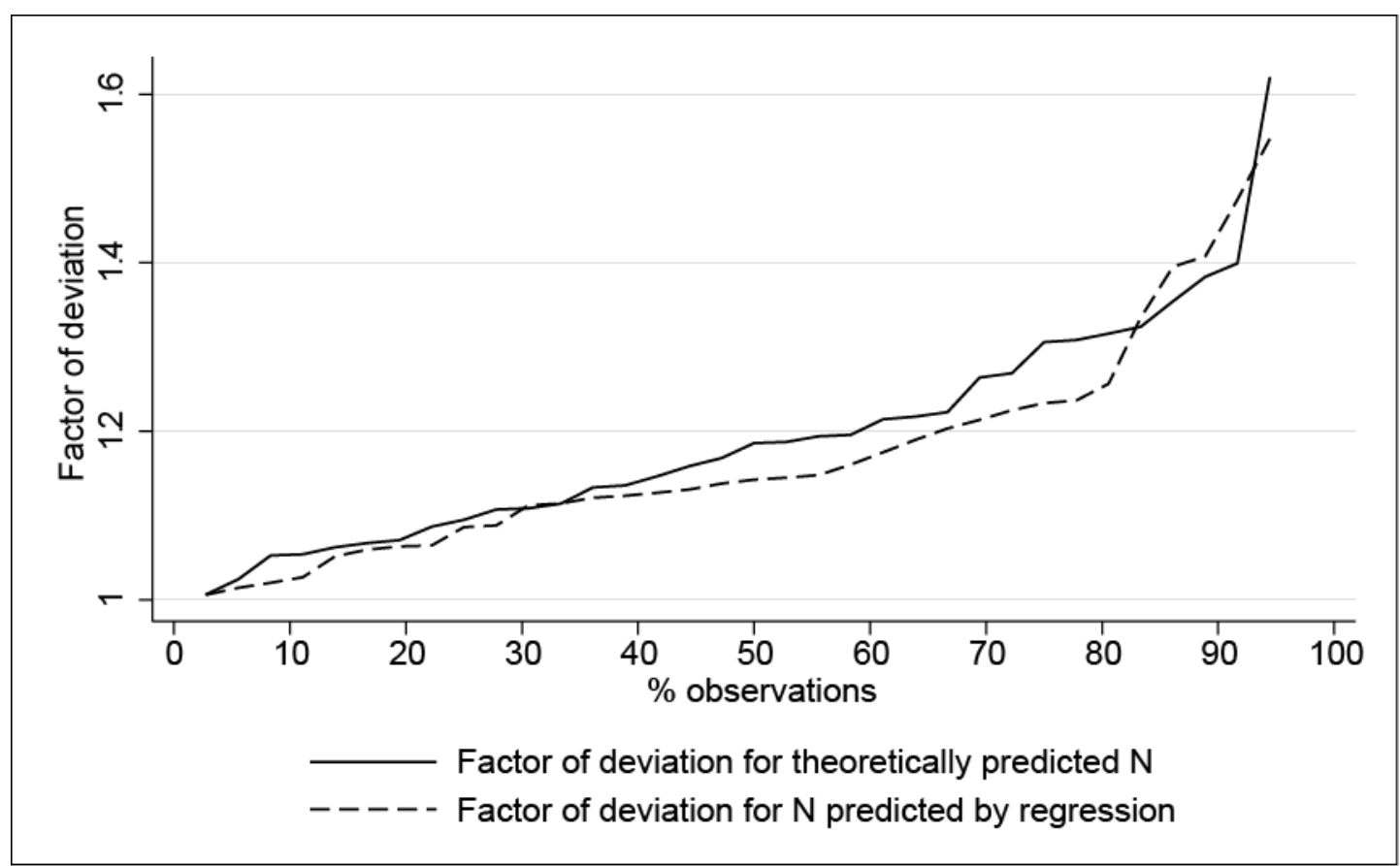

Notes: The figure shows the percentage of observations that lie within a certain factor from the expected values. E.g. about 60 percent of observations lie within the factor of 1.2 (i.e. divided or multiplied by 1.2) from the theoretically predicted N. Papua New Guinea not shown. 
Figure 5. Mean duration of cabinets vs the product of population and district magnitude cubed.

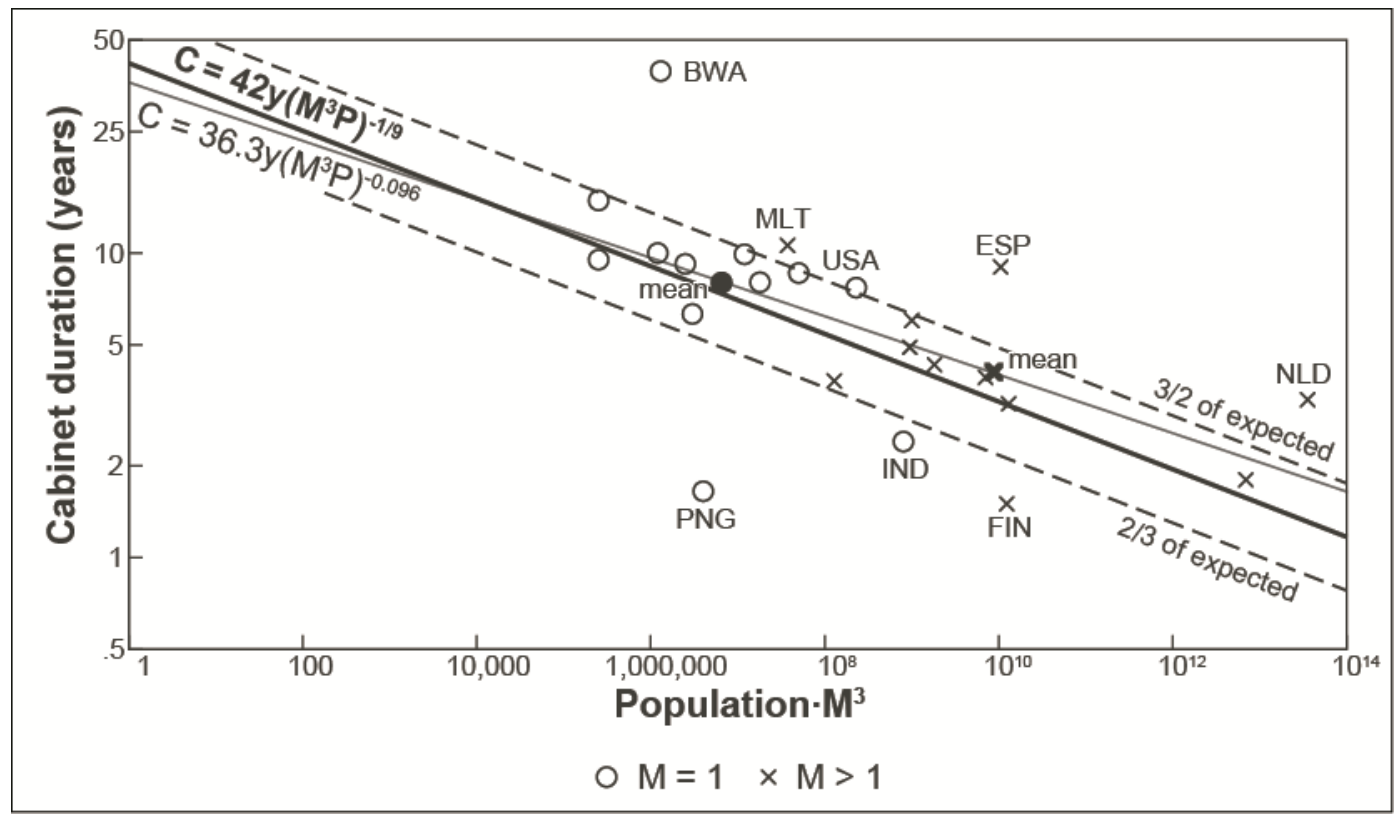

Notes: Bold line: theoretically based prediction $\left(\mathrm{R}^{2}=0.33\right)$. Thin line: OLS best fit between logarithms $\left(\mathrm{R}^{2}=0.38\right)$

Figure 6. Effective number of parties for given population and district magnitude

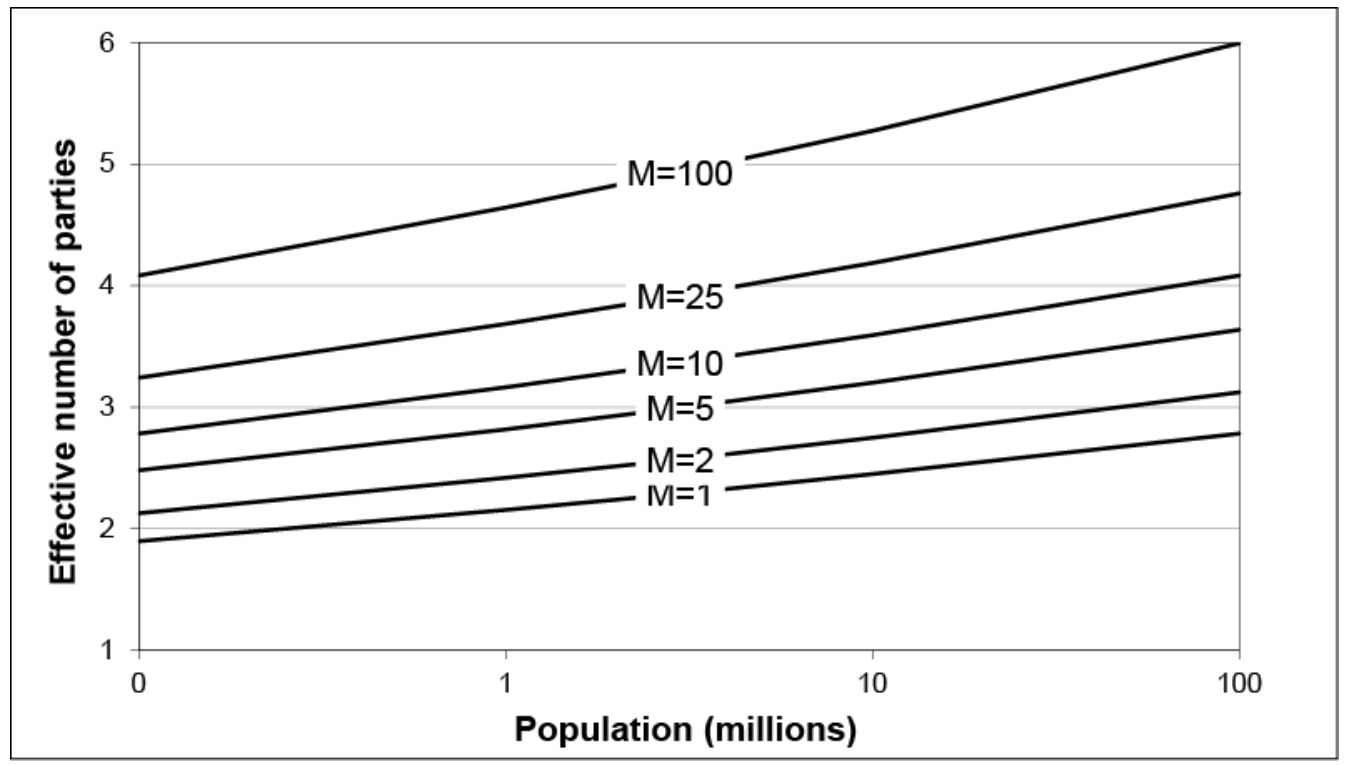


Figure 7. Residuals of largest seat share vs population.

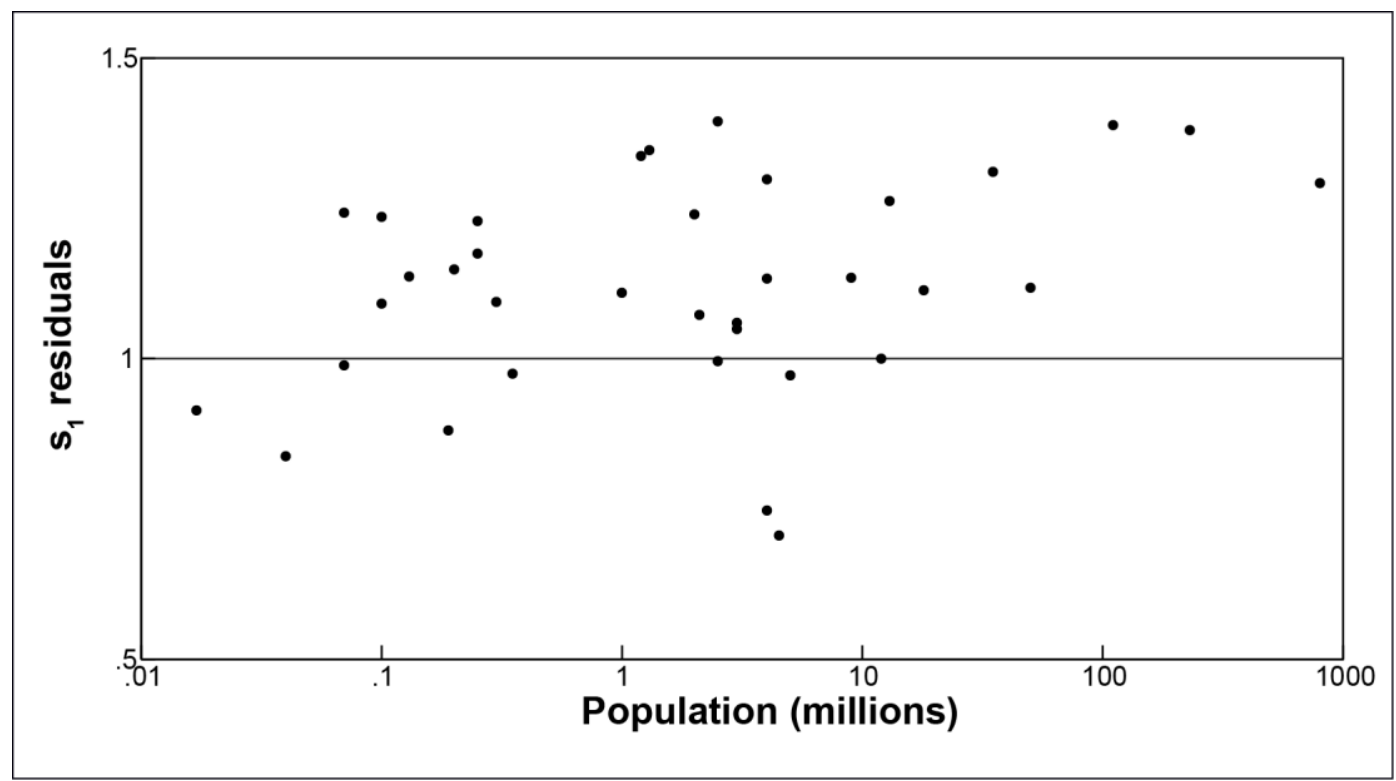

Figure 8. The largest seat share vs the product of population and district magnitude cubed, approximations for complex electoral systems included

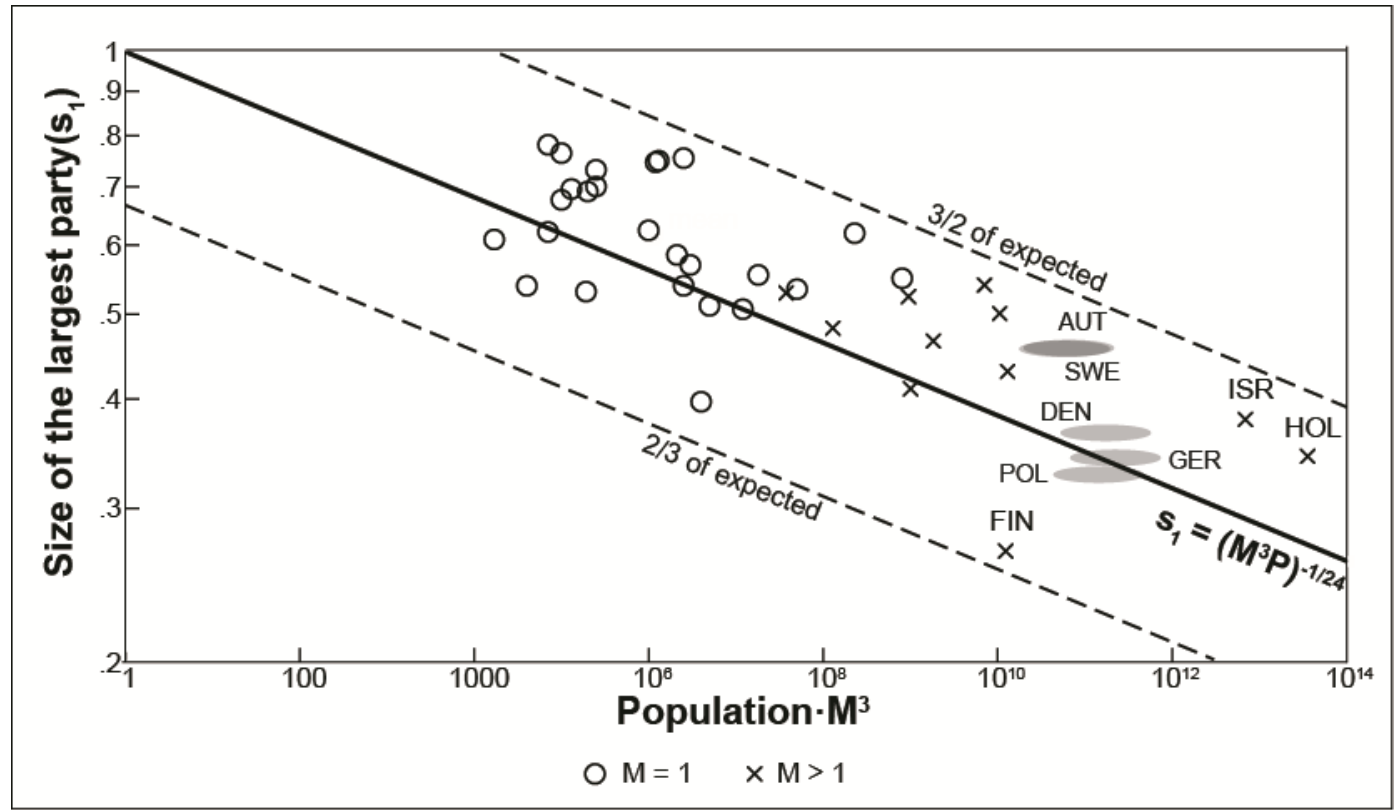




\section{TABLES}

Table 1. Population, seat allocation rule, mean district magnitude $(M)$, assembly size $(S)$, largest seat share $\left(s_{1}\right)$, effective number of legislative parties $(N)$, and cabinet duration $(C)$ for 25 oneseat and 11 multi-seat systems.

\begin{tabular}{|c|c|c|c|c|c|c|c|c|}
\hline & $\begin{array}{l}\text { Population } \\
\text { (million) }\end{array}$ & $M$ & $\begin{array}{l}M^{3} P \\
\text { (billion) }\end{array}$ & Rule & $S$ & $s_{1}$ & $N$ & $\begin{array}{l}C \\
\text { (years) }\end{array}$ \\
\hline Cook Islands 1965-99 & 0.017 & 1 & $1.7 \cdot 10^{5}$ & FPTP & 23.2 & 0.609 & 1.97 & \\
\hline St. Kitts $1980-2000$ & 0.04 & 1 & $4.0 \cdot 10^{5}$ & FPTP & 10.5 & 0.539 & 2.44 & \\
\hline Antigua 1980-99 & 0.07 & 1 & $7.0 \cdot 10^{5}$ & FPTP & 17.0 & 0.781 & 1.52 & \\
\hline Dominica $1975-2000$ & 0.07 & 1 & $7.0 \cdot 10^{5}$ & FPTP & 21.0 & 0.621 & 2.02 & \\
\hline Grenada 1972-2003 & 0.1 & 1 & $1.0 \cdot 10^{4}$ & FPTP & 15.0 & 0.676 & 1.71 & \\
\hline St. Vincent 1974-2001 & 0.1 & 1 & $1.0 \cdot 10^{4}$ & FPTP & 14.1 & 0.765 & 1.50 & \\
\hline St. Lucia 1974-2001 & 0.13 & 1 & $1.3 \cdot 10^{4}$ & FPTP & 17.0 & 0.696 & 1.66 & \\
\hline Samoa 1979-2001 & 0.19 & 1 & $1.9 \cdot 10^{4}$ & FPTP & 47.6 & 0.531 & 2.33 & \\
\hline Belize 1979-2003 & 0.2 & 1 & $2.0 \cdot 10^{4}$ & FPTP & 26.5 & 0.691 & 1.65 & \\
\hline Bahamas 1972-2002 & 0.25 & 1 & $2.5 \cdot 10^{4}$ & FPTP & 42.0 & 0.732 & 1.68 & 14.9 \\
\hline Barbados 1966-94 & 0.25 & 1 & $2.5 \cdot 10^{4}$ & FPTP & 26.0 & 0.700 & 1.76 & 9.5 \\
\hline Trinidad 1961-2001 & 1.2 & 1 & 0.0012 & FPTP & 36.0 & 0.746 & 1.82 & 10.0 \\
\hline Botswana 1965-2004 & 1.3 & 1 & 0.0013 & FPTP & 37.0 & 0.749 & 1.35 & $39.6+$ \\
\hline Norway 1882-1903 & 2.1 & 1 & 0.0021 & FPTP & 114.4 & 0.585 & 2.13 & \\
\hline Jamaica 1962-89 & 2.5 & 1 & 0.0025 & FPTP & 55.0 & 0.755 & 1.62 & 9.2 \\
\hline Denmark 1884-1913 & 2.5 & 1 & 0.0025 & FPTP & 109.9 & 0.539 & 2.51 & \\
\hline New Zealand 1946-96 & 3 & 1 & 0.003 & FPTP & 85.0 & 0.569 & 1.96 & 6.3 \\
\hline Papua New Guinea 1977-97 & 4 & 1 & 0.004 & FPTP & 108.0 & 0.397 & 5.98 & 1.7 \\
\hline Sweden 1887-1905 & 5 & 1 & 0.005 & FPTP* & 226.3 & 0.511 & 2.20 & \\
\hline Australia 1946-96 & 12 & 1 & 0.012 & STV & 128.0 & 0.507 & 2.22 & 9.9 \\
\hline Canada 1945-93 & 18 & 1 & 0.018 & FPTP & 270.0 & 0.555 & 2.37 & 8.0 \\
\hline United Kingdom 1945-97 & 50 & 1 & 0.05 & FPTP & 635.0 & 0.534 & 2.11 & 8.6 \\
\hline United States 1947-2001 & 230 & 1 & 0.23 & FPTP & 435.0 & 0.619 & 2.40 & 7.7 \\
\hline India 1977-96 & 800 & 1 & 0.8 & FPTP & 542.0 & 0.550 & 4.11 & 2.4 \\
\hline Geometric mean for $M=1$ & 1.14 & & & & 59.7 & 0.615 & 2.08 & 7.99 \\
\hline Malta 1966-87 & 0.3 & 5 & 0.038 & STV & 59.0 & 0.529 & 1.99 & 10.6 \\
\hline Luxembourg 1945-99 & 0.35 & 14.2 & 1 & $\mathrm{~L}$ & $56.4^{\mathrm{d}}$ & 0.411 & 3.36 & 6.0 \\
\hline Costa Rica 1953-98 & 2 & 7.8 & 0.95 & $\mathrm{~L}$ & 55.0 & 0.524 & 2.41 & 4.9 \\
\hline Ireland 1948-97 & 3 & 3.5 & 1.3 & STV & 154.0 & 0.482 & 2.84 & 3.8 \\
\hline Israel 1949-96 & 4 & 120 & 6900 & $\mathrm{~L}$ & 120.0 & 0.379 & 4.55 & 1.8 \\
\hline Norway 1945-97 & 4 & 7.7 & 1.8 & $\mathrm{~L}$ & 154.0 & 0.466 & 3.35 & 4.3 \\
\hline Finland 1945-2003 & 4.5 & 14 & 12.3 & $\mathrm{~L}$ & 200.0 & 0.268 & 5.03 & 1.5 \\
\hline Portugal 1976-2002 & 9 & 11.3 & 13 & $\mathrm{~L}$ & 249.0 & 0.430 & 3.33 & 3.2 \\
\hline Netherlands 1946-2002 & 13 & 140 & 35700 & $\mathrm{~L}$ & $137.7^{\mathrm{e}}$ & 0.344 & 4.65 & 3.3 \\
\hline Spain 1977-2004 & 35 & 6.7 & 10.5 & $\mathrm{~L}$ & 350.0 & 0.501 & 2.76 & 9.0 \\
\hline Japan 1946-96 & 110 & 4 & 7 & SNTV & 486.0 & 0.540 & 3.71 & 3.9 \\
\hline Geometric mean for $M>1$ & & & 10.85 & & 145.6 & 0.434 & 3.33 & 4.06 \\
\hline
\end{tabular}

Source: Adjusted from Taagepera and Sikk (2010) and Taagepera and Ensch (2006). Additional data based on Nohlen et al (2001) and Nohlen (2005).

Notes: Seat allocation rules: FPTP - First-Past-The-Post; STV - single transferable vote; L - list PR;

SNTV - single non-transferable vote.

* Multi-member districts in five largest towns (Mackie \& Rose 1974: 341) 
Table 2. Actual geometric means of system characteristics and predictions based on mean population, $24 M=1$ countries.

\begin{tabular}{lccc}
\hline & Actual Geometric Mean & Calculated from Mean Population & Difference \\
\hline Population & $1.14 \cdot 10^{6}$ & 104.6 & $+75 \%$ \\
Assembly size & 59.7 & 0.559 & $-9 \%$ \\
Largest seat share & 0.615 & 2.17 & $+4 \%$ \\
Effective number & 2.08 & & $-8 \%$ \\
of parties & & 7.35 yrs \\
Mean cabinet & 7.99 yrs & \\
duration* &
\end{tabular}

Table 3. Actual geometric means of system characteristics and predictions based on mean population, $11 M>1$ countries

\begin{tabular}{lccc}
\hline & Actual Geometric Mean & Calculated from Mean $P$ or & Difference \\
& $4.62 \cdot 10^{6}$ & $M^{3} P$ & \\
\hline Population & 145.3 & 166.6 & $+15 \%$ \\
Assembly size & $8.8 \cdot 10^{9}$ & & $-11 \%$ \\
Magnitude ${ }^{3}$ Population & 0.434 & 0.385 & $+7 \%$ \\
Largest seat share & 3.33 & 3.57 & $-19 \%$ \\
Effective number of & & & \\
parties & 4.06 yrs & $3.30 \mathrm{yrs}$ & \\
Mean cabinet duration & & & \\
\hline Note: Assembly size is calculated from $P$ the other outputs from $M^{3} P$ &
\end{tabular}

Note: Assembly size is calculated from $P$, the other outputs from $M^{3} P$. 
Table 4. Predicted characteristics for countries with nationwide PR, and factor by which the actual value is off.

\begin{tabular}{lcccccc}
\hline & \multicolumn{3}{c}{ ISRAEL } & \multicolumn{4}{c}{ NETHERLANDS } \\
& Predicted & Actual & Factor & Predicted & Actual & Factor \\
& & & & & & \\
\hline$s_{1}$ & 0.282 & 0.379 & 1.34 & 0.255 & 0.344 & 1.35 \\
$N$ & 5.41 & 4.55 & 1.18 & 6.17 & 4.65 & 1.33 \\
& & & & & & \\
(years) & 1.43 & 1.75 & 1.22 & 1.10 & 3.3 & 3.00 \\
\hline
\end{tabular}


Table 5. Comparison of theoretical and OLS coefficients and model fits

\begin{tabular}{|c|c|c|c|c|c|c|c|c|c|c|c|}
\hline & $\mathbf{S}_{\mathbf{1}}(\mathrm{M}=1)$ & & $\mathbf{S}_{1}$ & & & $\mathbf{N}$ & & & $\mathbf{C}$ & & \\
\hline & $\begin{array}{l}\text { theor. } \\
\text { model }\end{array}$ & OLS1 & $\begin{array}{l}\text { theor. } \\
\text { model }\end{array}$ & OLS1 & $O L S 2$ & $\begin{array}{l}\text { theor. } \\
\text { model }\end{array}$ & OLS1 & $O L S 2$ & $\begin{array}{l}\text { theor. } \\
\text { model }\end{array}$ & OLS1 & $O L S 2$ \\
\hline $\log \left(\mathrm{M}^{3} \mathrm{P}\right)$ & - & - & -0.042 & $\begin{array}{l}- \\
0.034^{* * *} \\
(0.005)\end{array}$ & - & 0.056 & $\begin{array}{l}0.054^{* * *} \\
(0.008)\end{array}$ & - & -0.111 & $\begin{array}{l}-0.096^{\text {**** }} \\
(0.027)\end{array}$ & - \\
\hline $\log M$ & - & - & $-0.125^{\mathrm{a}}$ & - & $\begin{array}{l}- \\
0.122^{* * *} \\
(0.021)\end{array}$ & $0.167^{\mathrm{a}}$ & - & $\begin{array}{l}0.153^{\text {*** }} \\
(0.033)\end{array}$ & $-0.333^{\mathrm{a}}$ & - & $\begin{array}{l}-0.270^{\text {*** }} \\
(0.089)\end{array}$ \\
\hline $\log \mathrm{P}$ & -0.042 & $\begin{array}{l}-0.025^{\text {** }} \\
(0.012)\end{array}$ & $-0.042^{\mathrm{a}}$ & - & $\begin{array}{l}-0.021^{*} \\
(0.011)\end{array}$ & $0.056^{\mathrm{a}}$ & - & $\begin{array}{l}0.059^{\text {**** }} \\
(0.018)\end{array}$ & $-0.111^{\mathrm{a}}$ & - & $\begin{array}{l}-0.126^{\text {*** }} \\
(0.063)\end{array}$ \\
\hline constant & 0 & $\begin{array}{c}-0.136 \\
(0.172)\end{array}$ & 0 & $\begin{array}{l}-0.019 \\
(0.095)\end{array}$ & $\begin{array}{c}-0.197 \\
(0.163)\end{array}$ & 0 & $\begin{array}{c}-0.017 \\
(0.145)\end{array}$ & $\begin{array}{c}-0.085 \\
(0.256)\end{array}$ & 3.74 & $\begin{array}{l}3.59^{\text {**** }} \\
(0.53)\end{array}$ & $\begin{array}{l}4.04^{\text {*** }} \\
(1.01)\end{array}$ \\
\hline \multicolumn{12}{|c|}{ Coefficients in exponential model ${ }^{b}$} \\
\hline $\mathrm{M}^{3} \mathrm{P}$ & - & - & -0.042 & -0.034 & - & 0.056 & 0.054 & - & -0.111 & -0.096 & - \\
\hline M & - & - & - & - & -0.122 & - & - & 0.153 & - & - & -0.270 \\
\hline $\mathrm{P}$ & -0.042 & -0.025 & - & - & -0.021 & - & - & 0.059 & - & - & -0.126 \\
\hline Multiplier ${ }^{\mathrm{c}}$ & 1 & 0.873 & 1 & 0.981 & 0.821 & 1 & 0.983 & 0.919 & $42 y r s$ & $36.3 y r s$ & $56.9 y r s$ \\
\hline SEE & 0.19 & 0.16 & 0.20 & 0.17 & 0.17 & 0.26 & 0.26 & 0.26 & 0.65 & 0.63 & 0.64 \\
\hline $\mathrm{R}^{2}$ & -0.22 & 0.17 & 0.35 & 0.55 & 0.57 & 0.54 & 0.56 & 0.56 & 0.33 & 0.38 & 0.39 \\
\hline $\mathrm{N}$ & 24 & 24 & 35 & 35 & 35 & 35 & 35 & 35 & 23 & 23 & 23 \\
\hline
\end{tabular}

Notes: Standard errors of OLS models are in parenthesis. OLS1 - models with $\log \left(M^{3} P\right)$ as an independent variable, OLS2 - models with log $M$ and $\log P$ entered individually.

${ }^{*} \mathrm{p}<.1,{ }^{* *} \mathrm{p}<.05,{ }^{* * *} \mathrm{p}<.01$

a Applies for OLS2 only.

${ }^{\mathrm{b}}$ See page 7 .

${ }^{c}$ multiplier $=\exp ($ constant $)$ 
Table 6. Estimates of predicted and actual $s_{1}$ in complex electoral systems

\begin{tabular}{|c|c|c|c|c|c|c|}
\hline & $\begin{array}{l}\text { Legal threshold } \\
\qquad T_{\text {legal }}\end{array}$ & $\begin{array}{c}\text { Estimated } \\
M_{e f f}\end{array}$ & $\begin{array}{l}\text { Estimated } \\
\qquad M^{3} P\end{array}$ & $\begin{array}{c}\text { Expected } \\
s_{1}\end{array}$ & $\begin{array}{c}\text { Actual } \\
s_{1}\end{array}$ & Years \\
\hline Germany & $5 \%$ & 14 & $270 \cdot 10^{9}$ & 0.33 & 0.33 & 1989-2005 \\
\hline Denmark & $2 \%$ & 37 & $253 \cdot 10^{9}$ & 0.33 & 0.35 & 1945-2007 \\
\hline Poland & $5 \%$ & 14 & $135 \cdot 10^{9}$ & 0.34 & 0.32 & 1991-2007 \\
\hline Sweden & $4 \% *$ & 9 & $52.5 \cdot 10^{9}$ & 0.39 & 0.44 & 1948-2006 \\
\hline Austria & $4 \%$ & 18 & $47 \cdot 10^{9}$ & 0.36 & 0.44 & 1945-2008 \\
\hline
\end{tabular}

Source: Parties and Elections in Europe, http://www.parties-and-elections.de/ (accessed 2 September 2009)

Notes:

* Corresponding to $M_{\text {eff }}=18$. Yet, Sweden has a very small number of national compensation mandates (39 out of the total 349) and in most districts $M<18$. The $4 \%$ threshold applies nationally (disregarding the alternative $12 \%$ district level threshold that has never been put into practice). Hence, our estimate of $M_{\text {eff }}$ is based on mean $M$ with an upper constraint of $M=18=$ $(75 \% / 4 \%)-1$. 


\section{Notes}

${ }^{1}$ We measured cabinet duration used 'average cabinet life I' (see Dodd 1976 and Lijphart 1999: 132-3). This index best fits the stipulated logical relationship.

${ }^{2}$ We analyze means rather than individual elections for several reasons. First, we believe that party systems are durable characteristics of political systems. Secondly, there is very little variation over time in our independent variables and in most dependent variables. Geometric means are less sensitive than arithmetic means to untypically high values of the variables.

${ }^{3}$ Other factors mentioned above that may affect party systems have in most cases been fairly constant in political systems under study here. Analyzing means rather than levels of dependent variables over time is justified here as country size and mean district magnitude stay constant over long periods and could not possibly explain fluctuations in party systems and cabinet duration over time.

${ }^{4}$ Coefficients from OLS models and indicators of fit of theoretical and OLS models are given in Appendix A. Here, the coefficient of determination for the predicted line is negative. This may look erroneous since the common range for $\mathrm{R}^{2}$ is from 0 to 1 . However, that strictly applies to OLS best fit lines only. For other lines, the $\mathrm{R}^{2}$ - as based on the most frequently used formula - can be negative. Other fitting methods that are less sensitive to outliers (such as robust regression, quantile regression and deepest regression, see Wilcox 2005) would result in similar best fit lines in Figure 1 and in the Figures below. For an extensive discussion on the properties and variants of $\mathrm{R}^{2}$ see Kvalseth (1985).

${ }^{5}$ SEE reflects the standard deviation of model residuals. While the widely used $\mathrm{R}^{2}$ shows predictive capability of the model (Lewis-Beck \& Skalaban 1990), SEE has certain advantages over $\mathrm{R}^{2}$ (see Achen 1990), especially as it has the same units as the dependent variable. As we use logarithms of our dependent variables throughout the study, SEE has to be transformed to make the units meaningful. If $\mathrm{SEE}=0.20$ as in the case of $\log s_{1}, \exp (0.20)=1.22$ is the standard (multiplicative) factor of deviation in $s_{1}$.

${ }^{6}$ With Papua New Guinea included, SEE $=0.26$ for both theoretical and OLS fit $\left(\mathrm{R}^{2}=0.54\right.$ versus $\mathrm{R}^{2}=$ 0.56). From the perspective of empirical model fitting it might be tempting to include logarithms of $M$ and $P$ independently - that does not only untie the coefficients but also frees up the exponent of $M$. The resulting coefficients $(\log M: 0.153$ and $\log P: 0.059)$ are strikingly close to the theoretical model $(\log M$ : $0.167=3 \times 0.056$ and $\log P: 0.056$ ); a trivial improvement in model fit would be accompanied by an increase in the degrees of freedom and thus a lower F-statistic. The same applies for the other two models discussed in this study - see Appendix A for models with $\log P$ and $\log M$ included separately. 
${ }^{7}$ We used operationalizations from Singer \& Stephenson 2009, adding fractionalization data from Alesina et al 2003 for small island states. Resulting models are available on request.

${ }^{8}$ Cabinet duration involves a parameter (42 years) determined empirically from the relationship between $N$ and $C$. No data on $P$ or $M$ enters this determination. 